\title{
Descobrindo a língua inglesa
}

\author{
Karlucy Farias de Sousa ${ }^{1}$ \\ Laianne Costa Batista ${ }^{2}$
}

\section{Resumo}

O curso "Descobrindo a Língua Inglesa" foi idealizado para capacitar os aprendizes do Vale do Jaguaribe a se expressar corretamente, confidentemente e fluentemente na fala e na escrita em inglês, compreender a língua inglesa, seja ela falada ou escrita, da forma como ela é usada nos dias de hoje e funcionar socialmente em uma variedade de contextos, sejam eles familiares ou desconhecidos, em um nível iniciante. Destarte, este relato objetiva descrever a terceira edição dessa experiência, destacar sua importância e apresentar os resultados desta ação de extensão que foi desenvolvida em 2017. Os materiais que foram utilizados foram articulados de uma forma que os aprendizes fossem expostos a recursos úteis na aprendizagem de inglês como língua estrangeira. Vinte e quatro aprendizes, tanto da comunidade interna (servidores efetivos, substitutos ou terceirizados e discentes) quanto externa, foram beneficiados por esta ação. Após concluírem o curso, os aprendizes se familiarizaram com as quatro habilidades comunicativas da língua inglesa, em nível iniciante; ampliaram sua consciência linguística, além de se sensibilizarem com os aspectos socioculturais de outros países.

Palavras-chave: Inglês. Abordagem Comunicativa. Curso de Extensão.

\begin{abstract}
"Descobrindo a Língua Inglesa" 3 was a course designed to enable Vale do Jaguaribe learners (in the countryside of Ceará) to express themselves correctly, confidently and fluently in speaking and writing in English; to understand the English language, whether it is spoken or written, as it is used today; and to function socially in a variety of contexts, whether they are familiar or unfamiliar, in an elementary level. Therefore, this report aims at describing the experience, at highlighting its importance and at presenting the results of this extension action which was developed in 2017. The materials were selected in a way that the learners were exposed to useful resources for learning English as a foreign language. Twenty-four learners from both the internal (civil servants, temporary or outsourced workers and students) and external community were benefited by this action. By completing the course, the learners became familiar with the four communicative skills of the English language in an elementary level as well as they increased their linguistic and sociocultural awareness.
\end{abstract}

Keywords: English. Communicative Approach. Extension Course.

\section{Considerações iniciais}

\footnotetext{
${ }^{1}$ Professora de Língua Inglesa no Instituto Federal de Educação, Ciência e Tecnologia do Ceará (IFCE - Limoeiro do Norte).

${ }^{2}$ Bolsista de pesquisa do Instituto Federal do Ceará - Campus Limoeiro do Norte.

${ }^{3}$ Em inglês, ter-se-ia algo como "Unraveling the English Language". Essa versão é de nossa autoria.
} 
É inegável a importância de estudar inglês, uma vez que essa é a principal língua da comunicação internacional. No mundo globalizado, pode-se ter várias oportunidades de contato com a língua inglesa (através da Internet, de filmes, da música e da televisão), mas muito dela é incompreensível para aprendizes de nível iniciante e intermediário (considerando que muitas pessoas acreditam que pode ser difícil e frustrante de aprender a partir deles). Saslow e Ascher (2011) afirmam que o ensino desse idioma não pode ser feito de maneira imprudente: é preciso ir além das peculiaridades culturais e linguísticas tradicionais. Gramática, vocabulário e a linguagem social precisam ser conectadas com as unidades comunicativas, ponderando que é indispensável preparar os aprendizes para que eles possam se comunicar com uma série de falantes de língua inglesa ao redor do mundo e mais de dois terços deles não são falantes nativos.

Desta maneira, é essencial que os aprendizes sejam apresentados a diferentes exemplos da língua inglesa em uso, assim como ter diversas oportunidades de praticá-la em suas quatro habilidades (auditiva, oral, escrita e leitura). Tendo em vista que um aprendiz típico tem chances limitadas para observar e praticar inglês fora da sala de aula, o objetivo dessa deve ser oferecer fontes ricas de insumo para observação, assim como oportunidades intensivas para práticas controladas e livres. Os aprendizes se beneficiam imensamente e aprendem com facilidade através da exposição a modelos de inglês falado e escrito do seu próprio nível de produtividade ou de um nível logo acima do seu (SASLOW; ASCHER, 2011). Ur (2012) defende a existência de uma forte relação entre a aprendizagem de uma língua estrangeira e o tempo de exposição dos aprendizes à língua estudada. Deste modo, os aprendizes também necessitam ser estimulados a buscar e observar a língua inglesa fora da sala de aula sempre que possível. Esses objetivos nortearam a preparação desse Curso de Extensão.

\section{Percurso metodológico}

A terceira edição do curso "Descobrindo a Língua Inglesa" foi iniciada em 30/05/2017 e concluída em 29/08/2017, com uma carga horária de $45 \mathrm{~h}$. Ele foi idealizado para os aprendizes adultos e jovens adultos, tanto da comunidade interna (servidores - sejam eles 
efetivos, substitutos ou terceirizados - e discentes) quanto externa, que são iniciantes (nunca estudaram inglês antes).

O curso foi divulgado através de cartazes, no endereço eletrônico do IFCE, na página do campus na Internet, nas páginas do campus nas redes sociais, através do Sistema Acadêmico e por e-mail. As vagas ofertadas foram completadas mediante o preenchimento da Ficha de Cadastro, a apresentação de um documento oficial de identificação com foto e uma cópia do diploma de conclusão de um Curso de Graduação (ou a declaração de estar cursando um Curso de Graduação).

O curso foi dividido em sete partes, de uma forma que os aprendizes fossem expostos a exemplos úteis em linguagem autêntica. O conteúdo do material utilizado foi projetado para ser atraente ao aprendiz de inglês. Eis a lista com as principais referências bibliográficas que foram utilizadas para preparar o material do curso:

FUCHS, M.; BONNER, M. Grammar Express: for self-study and classroom use. London: Pearson Longman, 2001.

MAURER, J. Focus on grammar 5: an integrated skills approach. 3rd ed. USA: Longman,2006.

OXEDEN, C.; LATHAM-KOENIG, C.; SELIGSON, P. New English File: Elementary. Oxford: Oxford University Press, 2004.

OXFORD. Oxford Learner's Dictionary of Academic English. 9a edição. Oxford University Press, 2015.

SASLOW, Joan; ASCHER, Allen. Top Notch: English for Today's World - Fundamentals. Second Edition. New York: Pearson Education, 2011.

THEWLIS, S. H. Grammar Dimensions 3. Boston: Thomson Heinle, 2000.

Quanto à forma como os alunos foram avaliados: a assiduidade e o comprometimento dos aprendizes com o curso foram observados, assim como a participação nas aulas. Trabalhos dirigidos foram feitos ao fim de cada uma das sete partes para avaliar se os conteúdos estudados estavam sendo assimilados. 


\section{A experiência sob o olhar de alguns alunos}

\subsection{Aluno 01}

Estudei inglês durante o Ensino Fundamental e Médio. Era um ensino bem básico. O que mais estudamos foi o verbo to be, além de

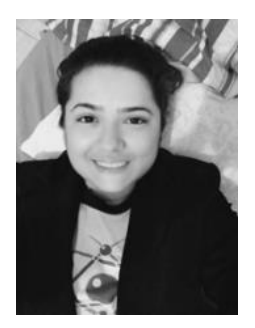
algumas regras de gramática e os professores, às vezes, traziam clipes de músicas internacionais, que eram as aulas que eu mais gostava. Embora eu gostasse muito, desde criança, de músicas em inglês, a disciplina não estava entre minhas favoritas.

Depois que terminei o Ensino Médio, passei a assistir muitas séries de TV, mas como não tinha muito conhecimento em inglês, preferia assistir sempre séries dubladas. Acontecia isso também com jogos de videogame, pois mesmo querendo muito jogar alguns, eu evitava os que eram em inglês; e com livros, já que nem me passava pela cabeça arriscar ler algum que não fosse traduzido para o português. Fiz um Curso Técnico e nele tive a disciplina de Inglês Instrumental, mas as aulas não eram muito interessantes e confesso que não lembro de praticamente nada do que estudei nela.

Meu próximo contato com a língua inglesa foi durante a Graduação, também com a disciplina de Inglês Instrumental, mas dessa vez a experiência foi completamente diferente. A professora era uma excelente educadora, tinha uma didática incrível e passava uma confiança tão grande para os alunos que até eu que sempre fui um pouco tímida passei a participar mais das aulas. Ao término da disciplina, inglês tinha se tornado uma das minhas paixões e eu definitivamente pretendia me aprofundar mais ainda no aprendizado da língua. Também passei a assistir séries sem legenda em português ou com o áudio original e a legenda em inglês; joguei vários jogos em inglês e comecei a ler mais textos e notícias em inglês. Fiquei bastante interessada quando soube que a mesma professora também ministrava Cursos de Extensão em inglês, além das aulas na Graduação. Quando o edital para a seleção de novos alunos para o nível iniciante saiu, me inscrevi para o Curso "Descobrindo a Língua Inglesa". O número de inscritos foi superior ao número de vagas. 
Ainda bem que o Índice de Rendimento Acadêmico (IRA) foi o critério de desempate e consegui uma vaga!

$\mathrm{Na}$ primeira aula, tivemos as apresentações entre os alunos, sendo feita uma dinâmica onde escrevíamos informações sobre nós mesmos em um pedaço de papel higiênico e não nos identificávamos. Depois, os papéis passavam para outras pessoas e íamos lendo as informações até descobrirmos de quem era o papel lido. Foi uma forma bem divertida e interessante para a turma se conhecer melhor. A professora também nos ensinou como cantar "Parabéns" em inglês, para quando algum aluno fizesse aniversário. Houve muita dificuldade na pronúncia da palavra birthday ${ }^{4}$, então ela nos ensinou uma dica sobre como pronunciar o th, que é uma das partes mais complicadas da língua, pois não temos um som parecido no português. Nós também aprendemos como perguntar e responder sobre como estamos nos sentindo e praticamos com os colegas.

Fomos apresentados ao material didático que seria utilizado na maioria das aulas, que foi o livro Top Notch, de Joan Saslow e Allen Ascher. Sete unidades foram selecionadas, cada uma contendo três lições. Dentro de cada unidade, há seções com vocabulários, atividades em dupla, atividades de Listening Comprehension ${ }^{5}$, gramática, uma seção chamada Conversation $\mathrm{Model}^{6}$, onde escutávamos, repetíamos diálogos e praticávamos com os colegas, personalizando a conversa para o nosso cotidiano. No final de cada unidade, há atividades para exercitar a gramática e o conteúdo estudado, além de assistirmos vídeos com o aúdio em inglês e depois respondermos questões para ver o que conseguimos entender.

Na hora da correção das atividades, a professora normalmente nos fazia revezar em dizer nossas respostas. Também tínhamos a Top Notch Pop Song ${ }^{7}$, uma canção bem divertida que envolve todos os temas estudados na unidade. Nessa parte da canção, sempre a praticávamos várias vezes antes de irmos para a versão karaokê. Era um dos momentos mais divertidos das aulas e ao longo do curso nós até cantamos várias vezes nossas Top

\footnotetext{
${ }^{4}$ Aniversário. Essa e todas as demais traduções foram feitas por nós.

${ }^{5}$ Compreensão Auditiva.

${ }^{6}$ Modelo de Conversação.

${ }^{7}$ Canção Pop do Top Notch.
} 
Notch Pop Songs favoritas. A seção final de atividades era chamada Just for fun ${ }^{8}$ e ela sempre trazia charadas em inglês e puzzles ${ }^{9}$ como caça-palavras, cruzadinhas, entre outras coisas.

Em uma das aulas, estudamos sobre nomes e ocupações. Aprendemos como falar várias profissões em inglês e praticamos como dizer nossas ocupações para os colegas. Também vimos como soletrar nomes e para isso praticamos bastante a pronúncia de cada letra do alfabeto. Foi bem divertido, porque nos confundíamos com a pronúncia de várias letras como a do $\mathrm{D}$ e a do $\mathrm{G}$ e mais ainda com o $\mathrm{A}$, o $\mathrm{E}$ e o I. Isso nos rendeu muito tempo pronunciando essas letras até conseguirmos falá-las rapidamente e sem errar uma única vez.

Em seguida, estudamos sobre como apresentar pessoas, como dizer para alguém seu nome e sobrenome e como conseguir informações para contato. Houve bastante prática nessa unidade, com a turma aprendendo como dizer seus números de telefone, seus emails, seus endereços e como perguntar os dados dos colegas.

Em outro momento, estudamos sobre como dizer as horas e praticamos utilizando os horários de vários países. Vimos como falar sobre a hora de um evento, os dias da semana, as preposições $a t$, on e $i n^{10}$, os meses do ano, os signos do zodíaco e os números ordinais. Como a maioria dos ordinais em inglês termina com as letras th, foi um teste de resistência conseguir pronunciar do 1 ao 50. Nós praticamos bastante mesmo a pronúncia deles. Depois praticamos como perguntar aos colegas seus aniversários.

O que tornou o curso tão bom não foi só o conteúdo estudado nele, mas sim a didática utilizada pela professora. Ela ensina de uma maneira tão incrível que cada aula era melhor que a anterior. Em uma das primeiras aulas, nós utilizamos o Plickers, cujo endereço eletrônico o define como "uma ferramenta simples que permite ao professor coletar dados de avaliação formativa em tempo real sem a necessidade de dispositivos estudantis" (PLICKERS, 2018). O professor precisa apenas dos cartões (cada plicker - Figura 1 - atribuído previamente a cada um de seus alunos) e de um dispositivo (celular ou tablet) para ler os cartões. No dia da aula, cada aluno recebeu um cartão com um único código visual (com

\footnotetext{
${ }^{8}$ Apenas por diversão.

${ }^{9}$ Quebra-cabeças.

${ }^{10} \mathrm{Em}, \mathrm{no}(\mathrm{a})$ ou equivalentes.
} 


\section{LínguaTec}

quatro lados: $A, B, C, D)$. O aluno segurava o cartão de tal forma que a letra que ele escolher para responder à pergunta precisa estar na parte superior do cartão.

Uma das coisas mais legais feitas foi a divisão da turma em dois grupos e em praticamente todas as aulas participávamos de competições amigáveis relacionadas aos conteúdos estudados. Uma das provas foi brincar de dominó em inglês para revisar o uso das preposições at, on e in; outra foi brincar de Chinese Whisper ${ }^{11}$ (Figuras 2, 3 e 4), utilizando siglas famosas em inglês para praticarmos nossa pronúncia do alfabeto.

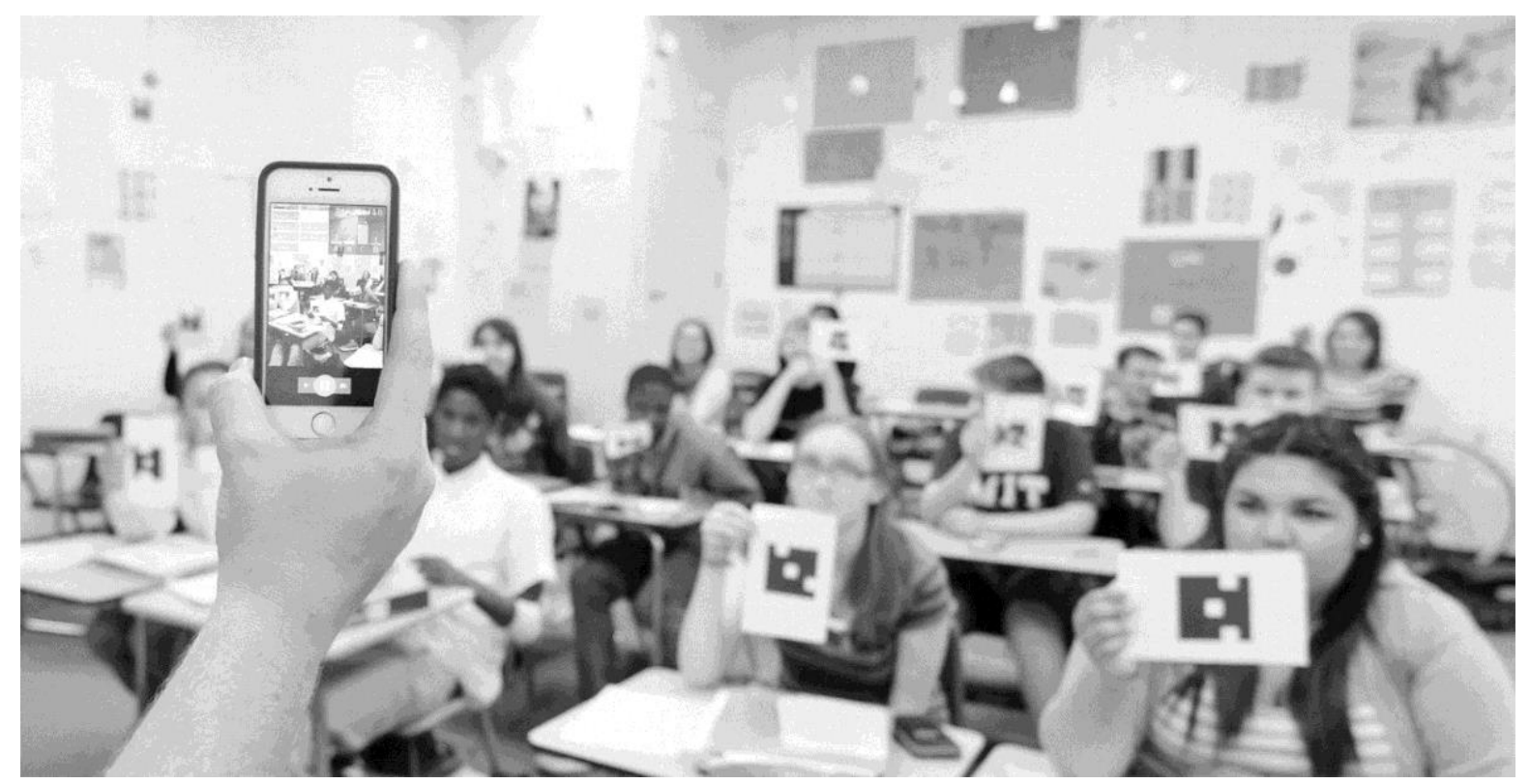

Figura 1: Plickers em uso.

Fonte: $\underline{\text { https://www.plickers.com/ }}$

\footnotetext{
11 Telefone sem fio - uma brincadeira na qual uma pessoa fala uma palavra ou frase no ouvido de outra pessoa ao seu lado, de modo que os demais participantes não escutem ou descubram imediatamente o que foi dito.
} 


\section{LínguaTec}

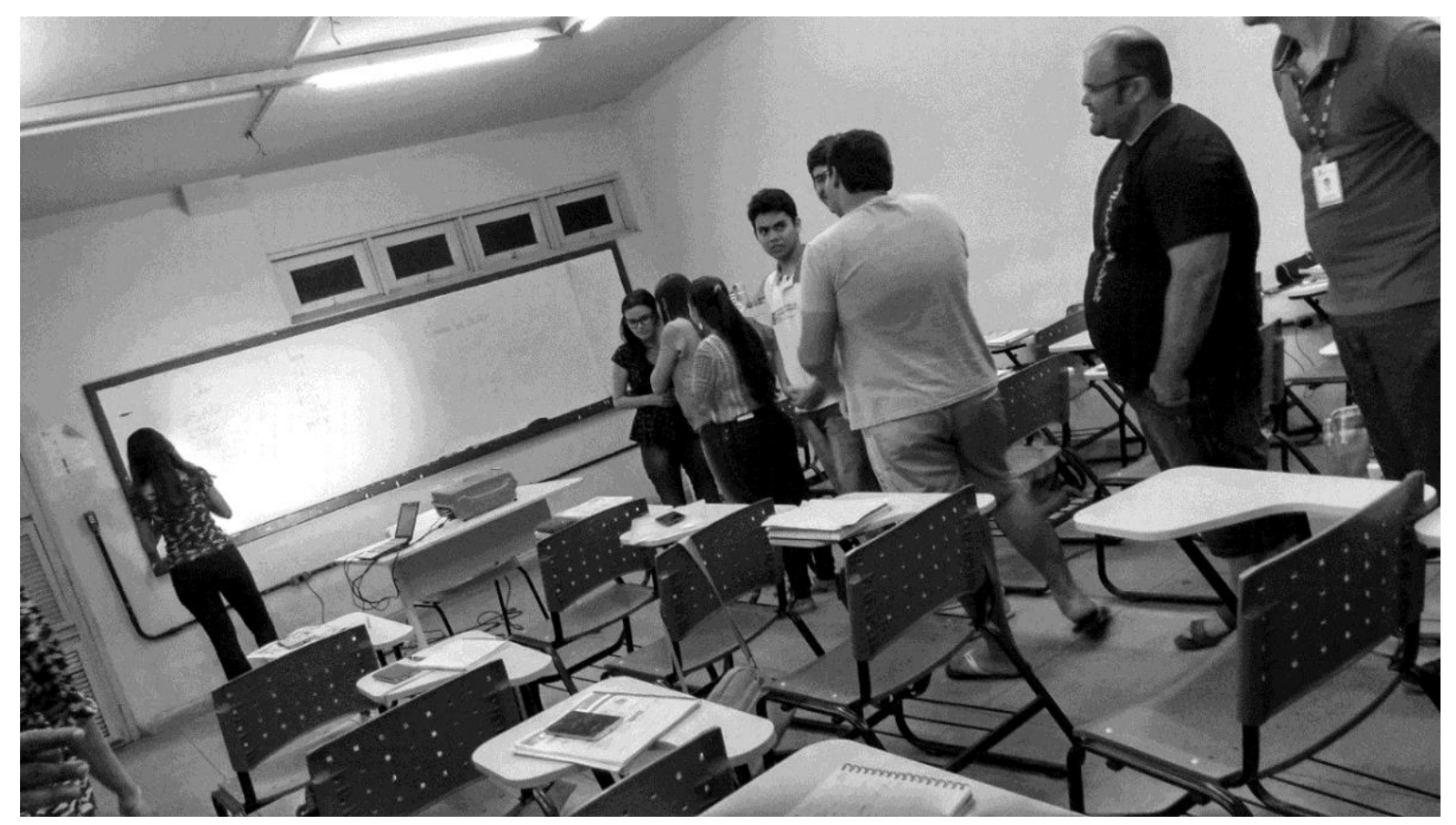

Figura 2: Grupo 1 repassando uma sigla.

Fonte: Arquivo pessoal das autoras.

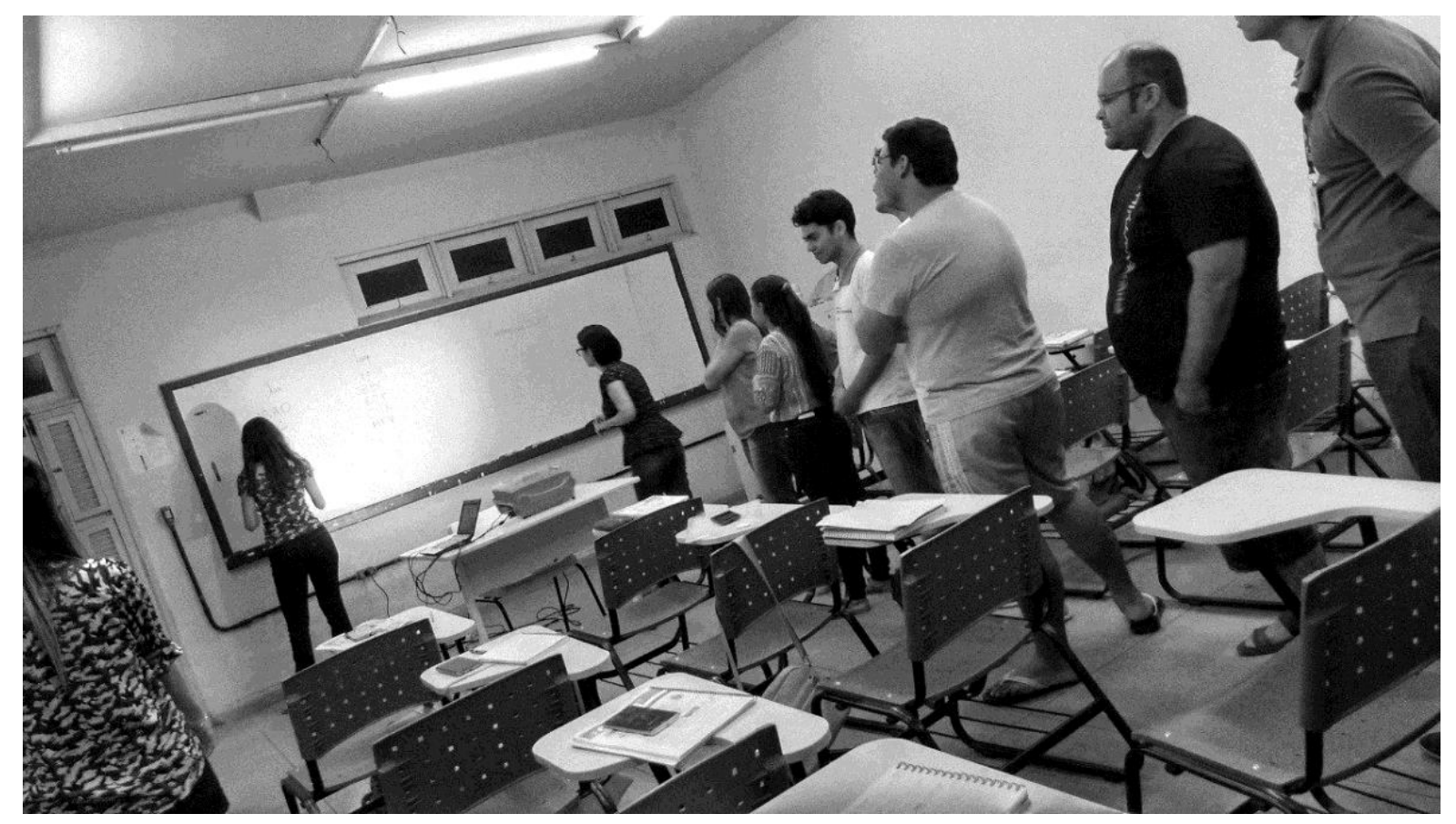

Figura 3: Grupo 1 brincando de Chinese Whisper.

Fonte: Arquivo pessoal das autoras. 


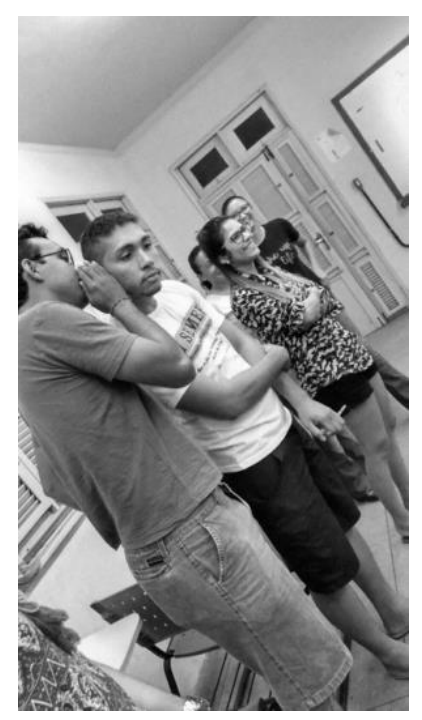

Figura 4: Grupo 2 repassando uma sigla.

Fonte: Arquivo pessoal das autoras.

No Review da Unidade Três, quando estávamos estudando lugares e como chegar neles, havia uma imagem com vários lugares e meios de transporte. Nós tivemos um minuto para estudar essa imagem e depois competimos para ver quem conseguia acertar mais perguntas sobre ela. Os vencedores ganharam lápis vindos diretamente dos Estados Unidos (Figuras 5 e 6). A professora os trouxe quando voltou do intercâmbio que fez lá.

Figura 5: As que os lápis dos

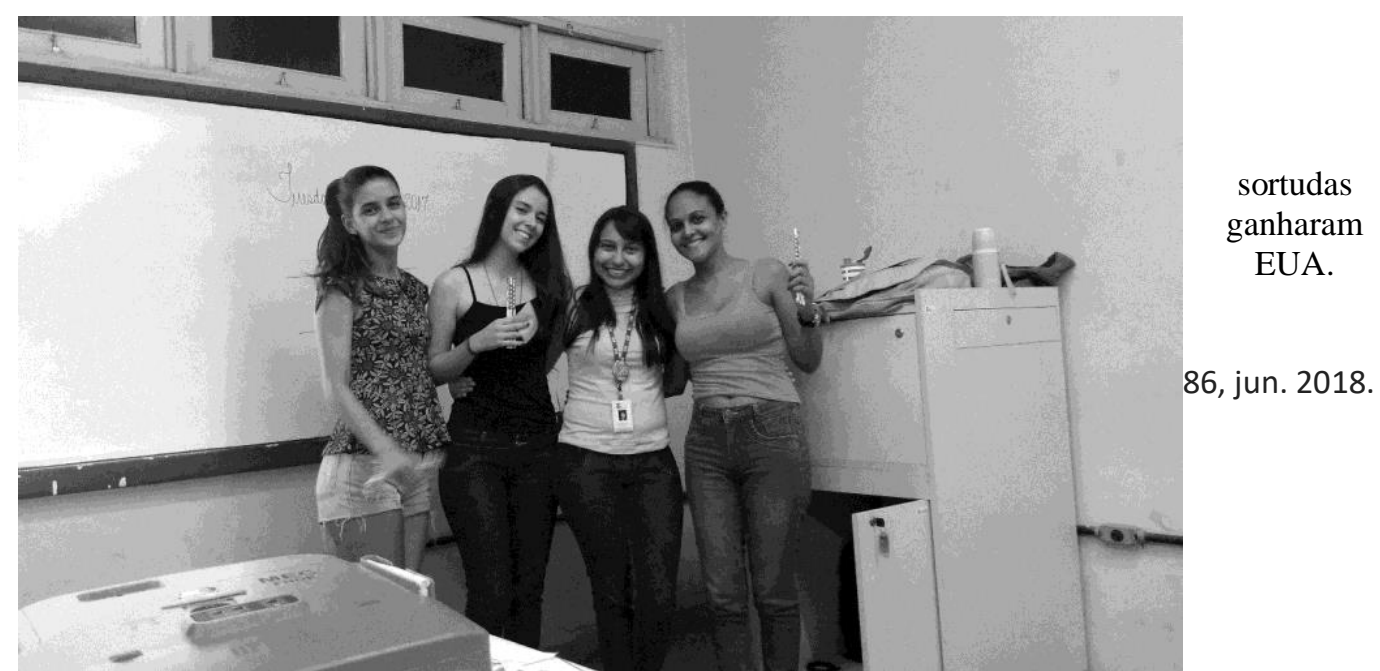




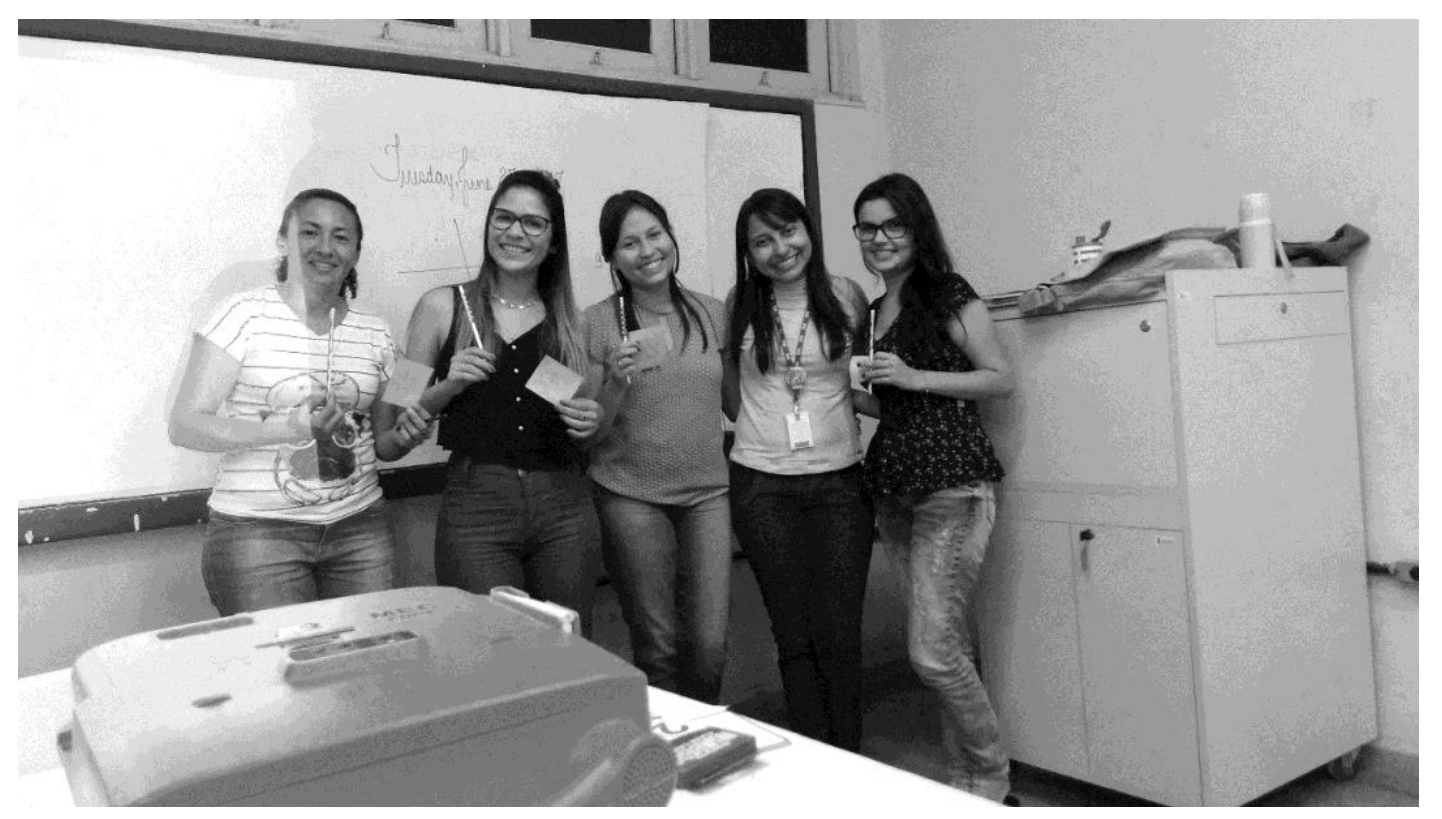

Fonte: Arquivo pessoal das autoras.

Figura 6: Mais sortudas que ganharam lápis dos EUA.

Fonte: Arquivo pessoal das autoras.

Outra prova foi sobre a Review da Unidade Cinco. Era uma página inteira com anúncios de vários eventos, com datas, horários e lugares e nós tivemos dois minutos para 
tentar lembrar o máximo de informações possíveis. Depois, nós competimos através de perguntas, usando um apagador e quem pegasse ele primeiro tinha o direito de responder (Figuras 7 e 8). Esse dia nos rendeu um momento icônico da disputa entre dois alunos, registrado nas Figuras 9 e 10.

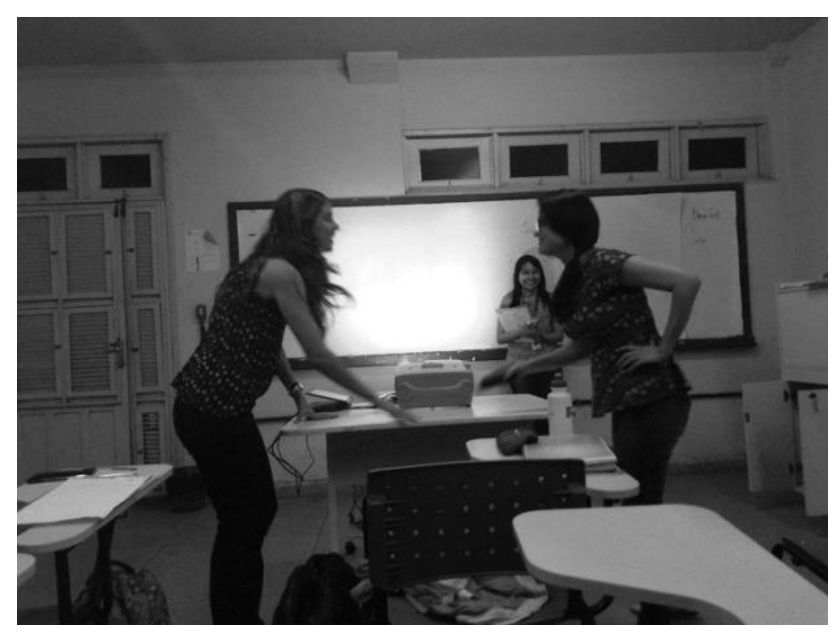

Figura 7: Perguntas e respostas sobre eventos.

Fonte: Arquivo pessoal das autoras. 


\section{LínguaTec}

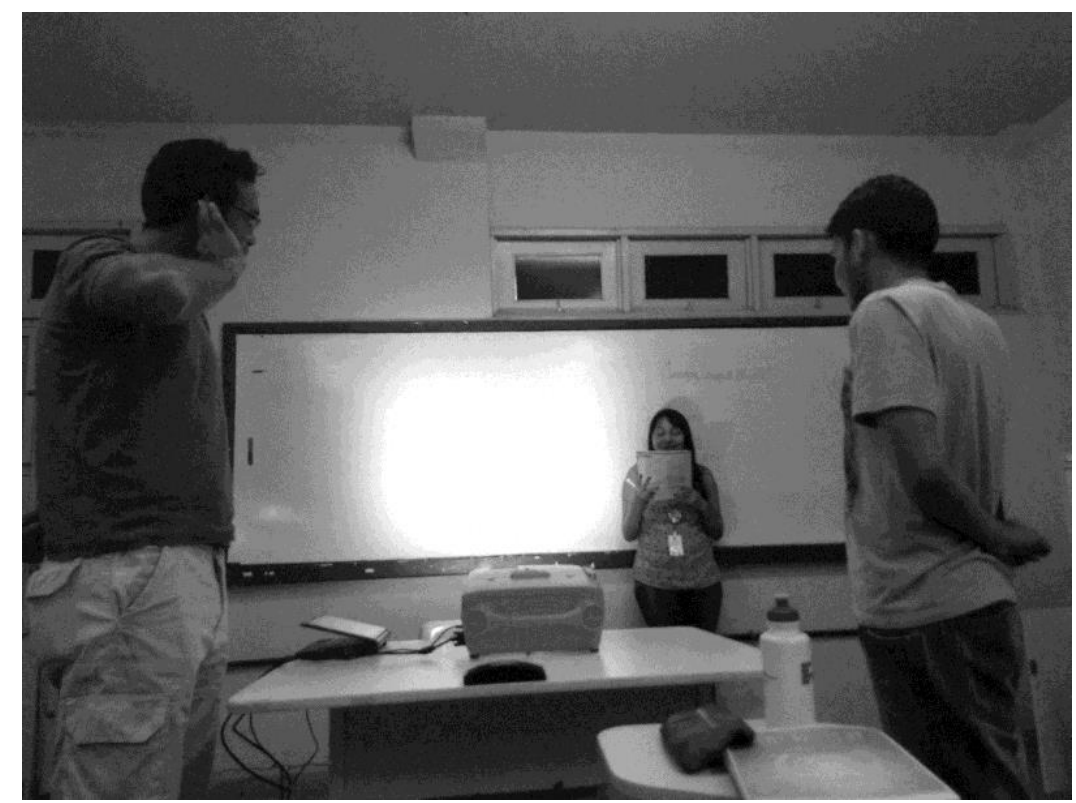

Figura 8: Alunos atentos às perguntas sobre eventos.

Fonte: Arquivo pessoal das autoras.

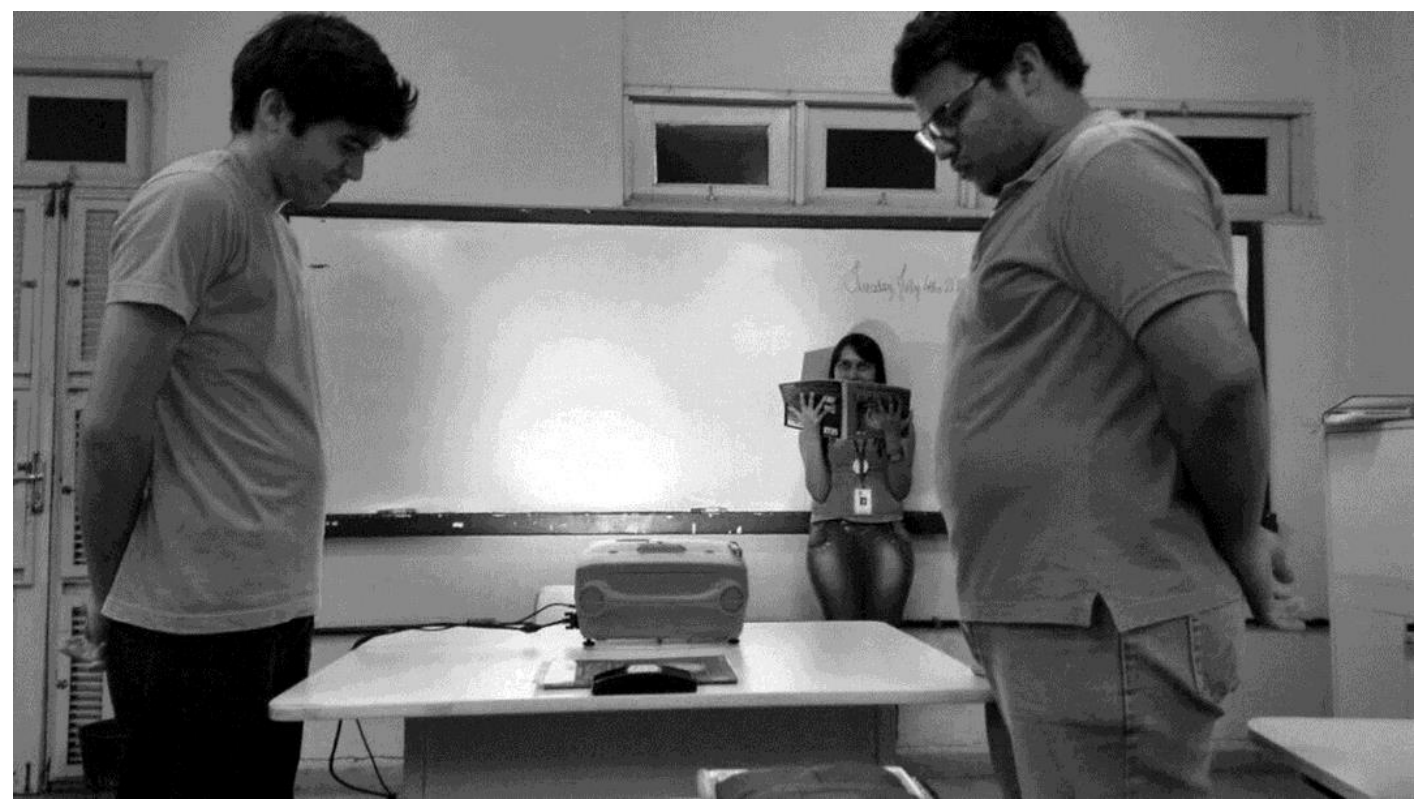

Figura 9: Alunos concentrados na "missão".

Fonte: Arquivo pessoal das autoras. 


\section{LínguaTec}

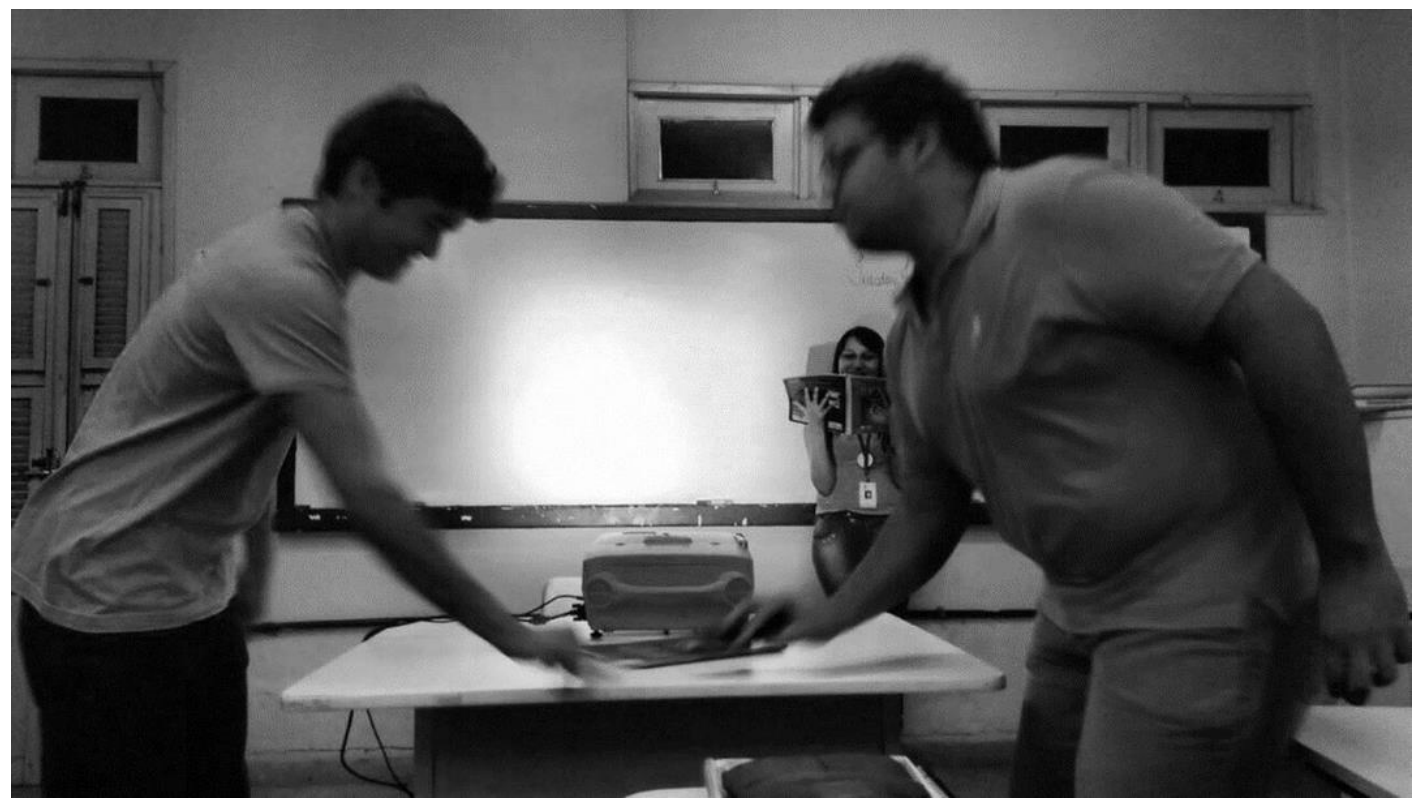

Figura 10: Disputa acirradíssima nas perguntas e respostas sobre eventos.

Fonte: Arquivo pessoal das autoras.

Outra coisa bem legal das aulas era estarmos sempre praticando o conteúdo em duplas ou grupos; com isso cada aluno acabava tendo contato com todos os outros colegas. Isso fazia com que sempre alguém que estava entendendo melhor o que estava sendo estudado naquela aula fizesse dupla com alguém que não estava entendendo bem e assim os dois acabavam aprendendo mais juntos.

\subsection{Aluno 02}

O Curso de Extensão "Descobrindo a Língua Inglesa" foi uma ótima experiência que pude ter durante o período de minha formação

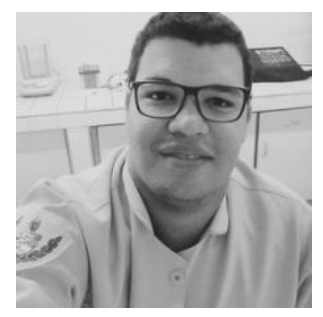
acadêmica. Fui motivado a entrar neste curso tanto por gostar de inglês, como por necessitar de conhecimentos que me auxiliassem na leitura de textos acadêmicos em inglês. $\mathrm{O}$ curso me ajudou bastante nesse quesito, visto que percebi uma melhor fluidez em minha leitura após passar a ter contato com a língua mais frequentemente.

O conteúdo abordado durante o curso foi bem completo e com muitas aplicações práticas nas mais diversas situações do cotidiano. Além disso, foram utilizados múltiplos recursos pedagógicos durante as aulas, o que as tornam mais atrativas e deixam o aprendizado 
do inglês mais divertido. Definiria a participação neste Curso de Extensão como prazerosa, pois em meio a tantas tarefas diárias, ir para o curso acabava sendo um momento divertido de aprendizado.

\subsection{Aluno 03}

O curso se dividia em módulos que se adequavam à evolução de aprendizagem do aluno dentro da Língua Inglesa, no qual era possível

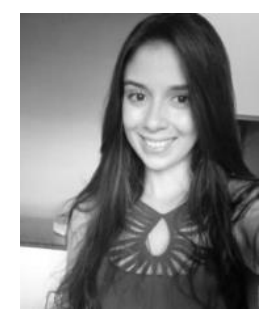
praticar as modalidades de escrita, fala e compreensão, também com atividades destinadas a fazer em casa. Durante as aulas fomos submetidos a atividades em grupo, bem como individuais.

A estratégia de ensino usada pela professora sempre foi muito dinâmica, divertida e acima de tudo muito didática, o que facilitava bastante a nossa compreensão. Ela sempre estava trazendo métodos inovadores, que permitiam uma maior interação da turma e interesse no aprendizado do idioma. O curso teve um impacto muito positivo, pois percebi melhora do meu desempenho no contato com o inglês!

\subsection{Aluno 04}

Normalmente, em um conteúdo ministrado em $4 \mathrm{~h}$ seguidas, em um certo ponto, acaba ocorrendo uma grande dispersão dos alunos, tornando-se

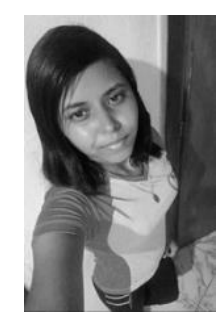
difícil cativar a atenção deles em relação ao conteúdo ministrado. Todavia, isso raramente ocorreu nas aulas de inglês, em virtude da metodologia do ensino da professora e da sequência didática que ela aplicava através das atividades de gramática, Listening Comprehension, Conversation Model, Top Notch Pop Song e as dinâmicas como o dominó com preposições em inglês e o telefone sem fio, onde exercitamos a pronúncia das letras citando algumas siglas de emissoras de TV como (HBO, FX, AXN, ABC, etc).

Essa sequência didática contribuiu bastante, tornando as aulas mais interessantes, onde todas as atividades se interligavam e complementavam nosso aprendizado de modo a facilitar muito mais a aquisição e a fixação do conteúdo ministrado. Em suma, era uma 
aprendizagem divertida, eficaz e, o mais importante, com qualidade, atingindo assim aos objetivos propostos pela professora.

\subsection{Aluno 05}

O curso de inglês "Descobrindo a Língua Inglesa" me proporcionou conhecer e ter um maior interesse neste idioma. Ele foi dividido em

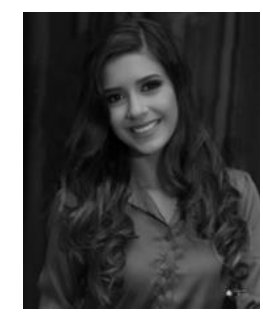
módulos, os quais evoluíam conforme os conhecimentos eram adquiridos. Cada módulo apresentava uma parte teórica e uma prática, onde aprendíamos as pronúncias das palavras a partir de diálogos com os colegas.

O curso explanava sobre as habilidades de leitura, escrita, fala e compreensão, com atividades individuais, coletivas, além das propostas para casa. A didática aplicada pela professora era sempre muito dinâmica, o que tornava as aulas mais interessantes, além de facilitar a aprendizagem.

\subsection{Aluno 06}

Durante o curso, todas as minhas expectativas foram superadas, pois antes de entrar pensava que seria um curso simples

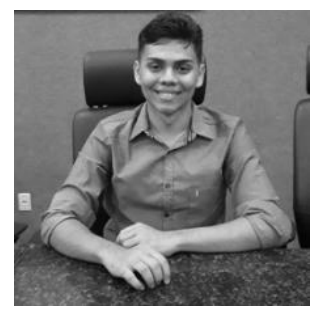
com apenas alguns conceitos básicos, mas durante o curso, a metodologia do ensino mostrou-se muito positiva, pois a cada lição que era ministrada, éramos apresentados a dinâmicas que faziam com que o conteúdo se fixasse cada vez mais, melhorando assim o conhecimento sobre a determinada lição.

As atividades realizadas mostraram-se de fácil compreensão e entendimento, sendo que entre elas tínhamos as seções de Conversation Model, onde praticávamos sobre determinado tópico da lição, podendo ser em grupo ou em duplas. No final de cada lição, também éramos apresentados a seção Top Notch Pop Song, onde, em forma de música, fazíamos um resumo de todo o conteúdo que aprendemos, sendo a aula encerrada de forma descontraída. 


\section{LínguaTec}

\section{Resultados}

Os aprendizes eram bastante motivados: eles tinham consciência das limitações que possuíam e da importância da língua para a carreira deles. No entanto, algumas dificuldades foram encontradas: alguns aprendizes precisaram faltar várias aulas por questões pertinentes à suas profissões e/ou vida acadêmica. Foram utilizadas as seguintes táticas para driblar os empecilhos: sempre que um aprendiz faltava, a professora tinha a atenção de informá-lo acerca do conteúdo que foi estudado na aula, pedia que ele fizesse em casa as atividades que foram desenvolvidas em sala e colocava-se a disposição para sanar eventuais dúvidas em aulas futuras.

Nessa edição, vinte e cinco aprendizes iniciaram o curso, porém, por questões profissionais, vinte e quatro o concluíram. Dos vinte e quatro aprendizes que concluíram o curso, quinze estavam cursando ou já haviam concluído um Curso de Graduação. Nove deles estavam cursando ou já haviam concluído um curso de Pós-Graduação (Especialização). A faixa etária dos beneficiários variava entre 24 e 40 anos. A área de Limoeiro do Norte e alguns municípios vizinhos, como Morada Nova, Quixeré e Tabuleiro do Norte foram atendidos. A Figura 11 apresenta essa turma no último dia de aula:

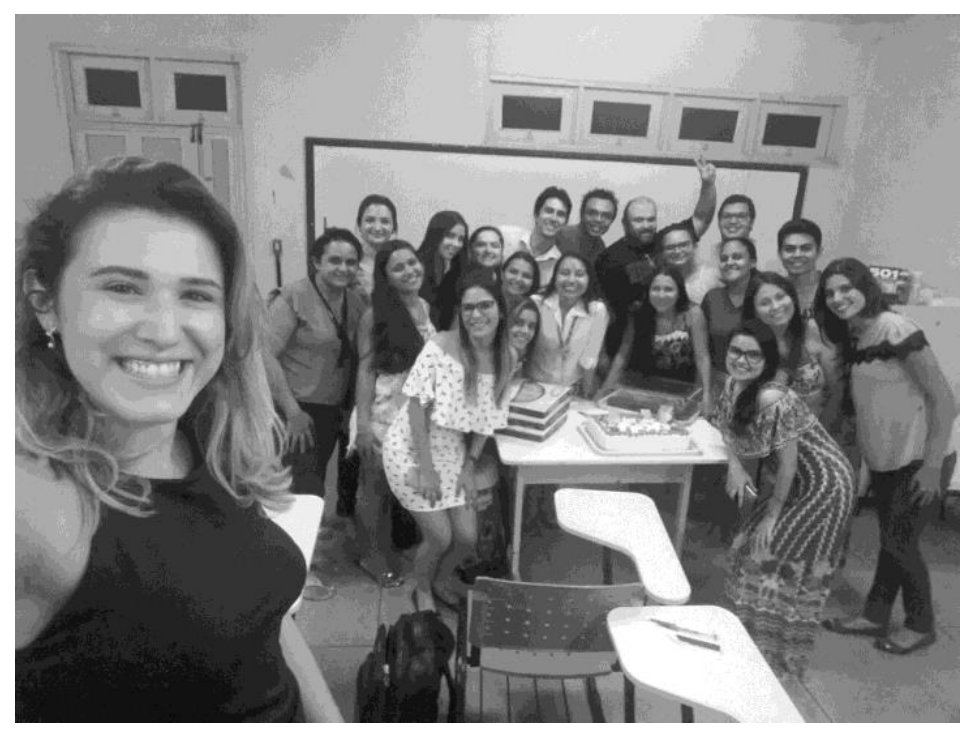

Figura 11: Festinha de encerramento.

Fonte: Arquivo pessoal das autoras. 


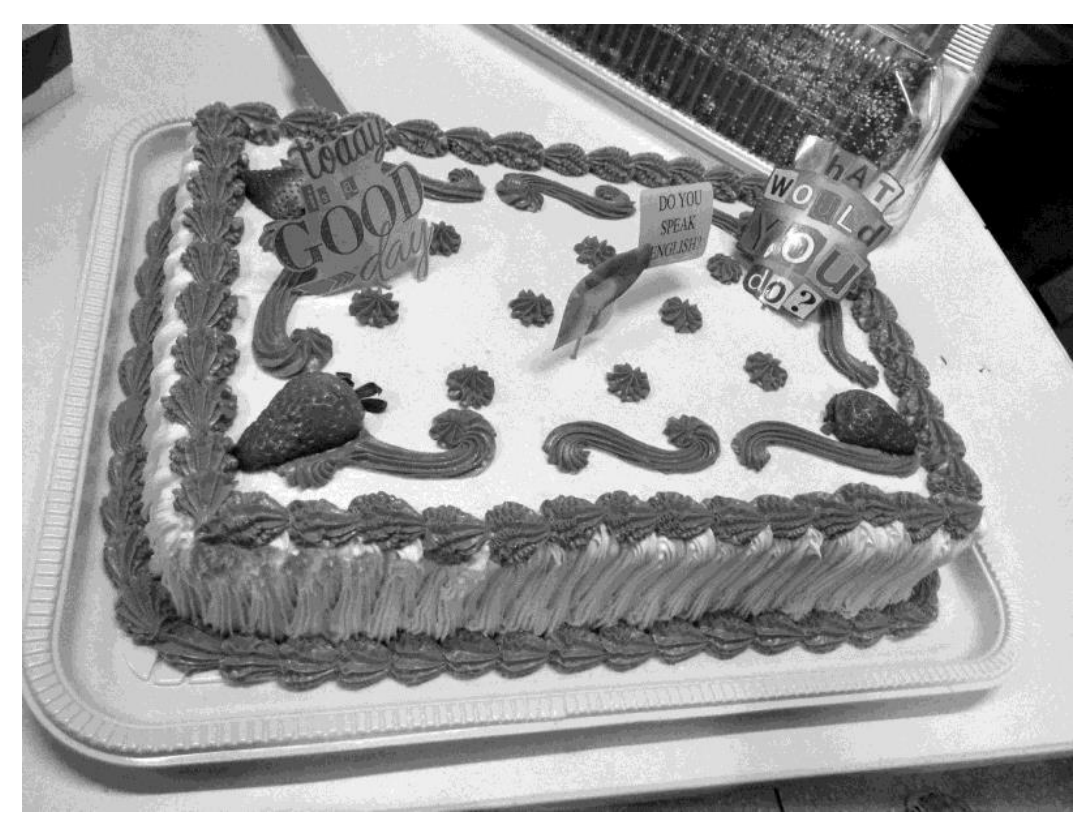

Esboço 12: Bolo temático da Festinha de Encerramento.

Fonte: Arquivo pessoal das autoras.

\section{Considerações Finais}

Durante as 45 horas do curso, os aprendizes foram expostos a recursos úteis na aprendizagem de inglês como língua estrangeira, para possibilitar aos aprendizes a compreensão, a fala, a leitura e a escrita em inglês, em nível iniciante, de uma maneira adequada, confiante e fluente.

Nesse momento, ainda não é possível afirmar se haverá uma nova edição do curso. Infelizmente, há apenas uma professora de inglês no campus para atender a demanda dos níveis Básico, Técnico, Tecnológico e de Pós-Graduação, dificultando o atendimento da demanda de Extensão. Até hoje, já houve três edições desse curso: a primeira ocorreu entre 20/05 e 11/12/2015; a segunda, por sua vez, entre 20/01 e 11/05/2016. É importante ressaltar que, embora o nível iniciante não seja suficiente para uma comunicação eficaz em qualquer situação, espera-se que ele seja suficiente para despertar o interesse do aluno para a continuidade do aprendizado da língua, após o fim do curso. Para acolher uma demanda 
dos alunos e dar continuidade ao "Descobrindo a Língua Inglesa", o curso "Desvendando a Língua Inglesa" foi lançado e já teve duas edições: a primeira ocorreu entre 20/01 e 15/05/2016 e a segunda entre 01/11/2017 e 28/03/2018. Pela razão anteriormente mencionada, também não é possível afirmar se haverá uma nova edição desse curso.

Como possível relevância a ser revelada a posteriori, espera-se ainda que este curso ajude os aprendizes na construção das habilidades comunicativas e da autoconfiança necessárias para navegar em situações sociais, turísticas e comerciais em cenários culturais desconhecidos, em nível iniciante.

\section{Agradecimentos}

As autoras agradecem imensamente aos alunos que disponibilizaram parte do seu tempo para darem seus depoimentos sobre o curso: Bruno Felipe de Oliveira, Candido Pereira do Nascimento, Deborah Lizandra Brito Lima Xavier, Kallina Santos Gonçalves e Reijane Alane da Silva Guilherme.

\section{REFERÊNCIAS}

PLICKERS. Disponível em: <https://www.plickers.com/>. Acesso em: 28 mar. 2018.

SASLOW, Joan; ASCHER, Allen. Top Notch: English for Today's World - Fundamentals. Second Edition. New York: Pearson Education, 2011.

UR, Penny. A Course in English language teaching. 2nd ed. Cambridge: Cambridge University Press, 2012.

Data de submissão: 31/03/2018. Data de aprovação: 16/05/2018. 